\title{
Effect of organic amendments on arsenic solubilization in soils during long-term flooded incubation
}

\author{
A. Suda ${ }^{1}$ T. Makino ${ }^{1}$
}

Received: 5 April 2016/Revised: 19 May 2016/Accepted: 27 June 2016/Published online: 26 July 2016

(C) Islamic Azad University (IAU) 2016

\begin{abstract}
Rice consumption is considered an important arsenic source for the population in Asian countries. Previous studies showed increase in arsenic solubility in flooded soils and arsenic uptake by rice plants with the application of organic amendments, while contrasting results were also reported. Here, we comprehensively examined the effect of three types of organic amendments on arsenic solubility during long-term flooded soil incubation. The amendments examined were categorized as (1) plant-based composts, (2) cattle manures, and (3) fermented livestock (swine and poultry) droppings. The dissolved arsenic in all soils with fermented livestock dropping was significantly greater than that in control soils at 10 and 39 days after incubation. The soils with two cattle manures also contained significantly greater amounts of dissolved arsenic than control soils at day 39 , while the rest of the amendments did not increase arsenic solubility. At day 80, the amount of dissolved arsenic in all soils became comparable. Tukey's test demonstrated that the relative ratio of dissolved arsenic in soils with fermented livestock droppings to control soils was significantly greater than those with the plant-based composts and cattle manures at days 10 and 39. Furthermore, the solubilizing effect of some organic amendments was mostly explained by promotion of decrease in soil Eh, rather than increase in dissolved organic carbon. Thus, it could be concluded that fermented livestock droppings potentially have a greater risk of solubilizing As than plant-based composts and cattle manures, because of their greater ability for accelerating soil reduction, associated with their higher bio-decomposability.
\end{abstract}

A. Suda

suda_aomi@affrc.go.jp

1 Institute for Agro-Environmental Sciences, NARO, 3-1-3 Kannondai, Tsukuba, Ibaraki 305-8604, Japan
Keywords Arsenic · Flooded incubation · Organic amendment $\cdot$ Redox potential $\cdot$ Soil

\section{Introduction}

Arsenic in soil environments predominantly exists as two inorganic species, namely arsenite [As(III)] and arsenate [As(V)]. Additionally, small amounts of monomethylarsonate and dimethylarsenate, which are methylated species, have also been found in soil extracts (Bissen and Frimmel 2000; Pongratz 1998). Arsenic(III) has greater toxicity than $\mathrm{As}(\mathrm{V})$, and the methylated As is much less toxic than inorganic ones (Jain and Ali 2000).

It is well known that As retention is highly associated with the amounts of iron (Fe) oxides (oxalate- and dithionite-extractable $\mathrm{Fe}$ ) and amorphous aluminum (Al) minerals (oxalate-extractable $\mathrm{Al}$ ) in soils (Livesey and Huang 1981; Jiang et al. 2005). Moreover, As(III) adsorbs onto soils more weakly than $\mathrm{As}(\mathrm{V})$ under most conditions (Manning and Goldberg 1997). Therefore, As easily solubilizes under water-flooded conditions like paddy soils, through the reductive dissolution of As-bearing $\mathrm{Fe}$ oxides and the redox transformation of $\mathrm{As}(\mathrm{V})$ to soluble As(III) (Hindersmann and Mansfeldt 2014; Weber et al. 2010). Consequently, paddy rice accumulates much more As than upland crops (Williams et al. 2007), and rice would be a significant dietary source of As, especially of inorganic As, for the population in Asian countries (Mondal and Polya 2008; Oguri et al. 2014). In 2014, the Codex Alimentarius Commission determined the maximum permitted concentration for inorganic As in polished rice $\left(0.2 \mathrm{mg} \mathrm{kg}^{-1}\right)$. Therefore, the As concentration in rice grains should be more carefully controlled, even in fields that are not Aspolluted. 
Organic amendments (OAs) have frequently been applied to paddy fields for improving soil physicochemical properties and/or supplying macro- and micronutrients for rice plants. Organic matter potentially insolubilizes As through several mechanisms, such as binding of As with phenolic $\mathrm{OH}$, carboxylate, and sulfhydryl groups with/ without ternary complex (cation bridging) (Thanagalasingam and Pickering 1986; Buschmann et al. 2006; Langner et al. 2011). Das et al. (2005) reported the decrease in sodium hydrogen carbonate-extractable As during submerged soil incubation with a well-decomposed farm yard manure and vermicompost. Rahaman et al. (2011) found that the application of OAs, and their combination, significantly decreased the As load of rice plants. On the other hand, organic matter induces chemical reduction in soil substances, competes for sorption sites with As, and forms soluble complexes with As (Xie and Huang 1998; Grafe et al. 2001; Wang and Mulligan 2006). This combination results in a potential increase in As solubility and bioavailability. The application of OAs promotes As solubilization and As uptake by rice plants (Xie and Huang 1998; Norton et al. 2013), although the timing of application (Honma et al. 2012) and its combination with water management (Ma et al. 2014) affect its impact.

There are various types of OAs, and their effect on As dynamics and plant availability should be different depending on their properties. For example, the addition of a fermented poultry dropping significantly increased dissolved As, while a composted bark did not, under the same conditions of flooded soil incubation (Suda et al. 2015). However, to the best of our knowledge, no research has been reported on a comprehensive examination of As solubilization in flooded soils with a focus on the properties of organic amendments (OAs).

Therefore, three types of OAs, namely (1) plant-based composts (PBCs), (2) cattle manures (CMs), and (3) fermented livestock (swine and poultry) droppings (FLDs), were prepared based on their major raw materials. The main objective of the present study was to compare the ability of these types of OAs to change As solubility in soil during long-term flooded incubation. This work was performed in the Institute for Agro-Environmental Sciences, National Agriculture and Food Research Organization (May 2015-March 2016).

\section{Materials and methods}

\section{Soil and organic amendments}

Surface paddy soil was collected in Japan in 2014 and passed through a 2-mm mesh sieve and then stored at $4{ }^{\circ} \mathrm{C}$ until use. Aliquots of the soil samples were air-dried and used for analysis of their physicochemical properties. The soil properties were reported by Suda et al. (2016). Briefly, the total carbon, total nitrogen, oxalate-extractable Fe, dithionite-citrate-extractable $\mathrm{Fe}$, and hydrochloric acid $\left(1 \mathrm{~mol} \mathrm{~L}^{-1}\right)$-extractable As was $54.3 \mathrm{~g} \mathrm{~kg}^{-1}, 3.99 \mathrm{~g} \mathrm{~kg}^{-1}, 20.8 \mathrm{~g} \mathrm{~kg}^{-1}, 34.1 \mathrm{~g} \mathrm{~kg}^{-1}$, and $7.42 \mathrm{mg} \mathrm{kg}^{-1}$, respectively. The soil was not polluted soil, as defined by the Agricultural Land-Soil Pollution Prevention Law in Japan.

Selected information about the OAs used is listed in Table 1. These OAs were commercially obtained except for amendment $\mathrm{E}$ (straw compost). They were milled and passed through 1-mm mesh sieves after their water content was reduced, if needed. However, they were not dried out to avoid the loss of volatile substances. Their ratios of carbon to nitrogen $(\mathrm{C} / \mathrm{N})$ were from 5.1 to 45.7 , and the average of each type of $\mathrm{OA}$ increased in the order FLDs $<$ CMs $<$ PBCs. Arsenic content was low, in the range $0.50-5.23 \mathrm{mg} \mathrm{kg}^{-1}$.

\section{Soil incubation}

Soil incubation experiments were set up for soil solution sampling ("Soil solution sampling and analysis for dissolved arsenic, iron, and organic matter" section) and $\mathrm{Fe}$ (II) extraction ("Extraction and measurement of ferrous iron in incubated soils" section) using the following procedure: Moist soil (10 g, oven-dried) and OA (0.05 g, oven-dried) were mixed with ultra-pure water to bring the total water volume to $30 \mathrm{~mL}$ in $50-\mathrm{mL}$ glass vials. Similar vials without OA were also prepared. The glass vial was covered with a butyl rubber cap and then tightly sealed with an aluminum cap after $\mathrm{N}_{2}$ gas purging for 2 min. The capped vial was manually shaken well, and then, it was incubated at $30{ }^{\circ} \mathrm{C}$ for a specific number of days. The vial was manually shaken every second or third day. The incubation was carried out in triplicate.

\section{Soil solution sampling and analysis for dissolved arsenic, iron, and organic matter}

After incubation, each supernatant in the vial was sampled with a syringe connected to a needle (NN-2360C, Terumo Corporation, Tokyo, Japan) with a $0.2-\mu \mathrm{m}$ filter (DG2M330, Spectrum Laboratories, Inc., Rancho Dominguez, CA, USA). The sampling unit was preliminarily purged with $\mathrm{N}_{2}$ gas. The collected filtrate (approximately $9 \mathrm{~mL}$ ) was mixed with $1 \mathrm{~mL}$ of $1.6 \mathrm{~mol} \mathrm{~L}^{-1} \mathrm{HNO}_{3}$ to prevent $\mathrm{Fe}$ hydroxide precipitation and then stored at $4{ }^{\circ} \mathrm{C}$ until analysis. The $\mathrm{pH}$ and Eh of the residual suspension were also measured, with a glass electrode and a combined electrode (platinum and silver-silver chloride electrode, $3 \mathrm{~mol} \mathrm{\textrm {L } ^ { - 1 }}$ potassium chloride electrolyte), respectively, under $\mathrm{N}_{2}$ gas. 
Table 1 Fundamental information on organic amendments used

\begin{tabular}{|c|c|c|c|c|c|c|}
\hline Amendment & Main raw material & Additives & As $\left(\mathrm{mg} \mathrm{kg}^{-1}\right)$ & $\mathrm{C}\left(\mathrm{g} \mathrm{kg}^{-1}\right)$ & $\mathrm{N}\left(\mathrm{g} \mathrm{kg}^{-1}\right)$ & $\mathrm{C} / \mathrm{N}$ \\
\hline \multicolumn{7}{|c|}{ Plant-based compost (PBC) } \\
\hline A & Bark & - & 4.18 & 343 & 16.0 & 21.4 \\
\hline $\mathrm{B}$ & Bark & - & 2.05 & 444 & 14.0 & 31.8 \\
\hline $\mathrm{C}$ & Cut branch & Cattle dropping & 2.94 & 311 & 18.5 & 16.8 \\
\hline $\mathrm{D}$ & Wood chip & Horse dropping & 1.37 & 471 & 10.3 & 45.7 \\
\hline $\mathrm{E}$ & Straw & - & 4.03 & 228 & 18.7 & 12.2 \\
\hline Average & & & 2.92 & 359 & 15.5 & 25.6 \\
\hline \multicolumn{7}{|c|}{ Cattle manure $(\mathrm{CM})$} \\
\hline $\mathrm{F}$ & Cattle dropping & Sawdust & 0.50 & 433 & 25.3 & 17.1 \\
\hline G & Cattle dropping & Sawdust & 0.69 & 385 & 32.8 & 11.7 \\
\hline $\mathrm{H}$ & Cattle dropping & Sawdust & 3.41 & 329 & 20.1 & 16.4 \\
\hline I & Cattle dropping & Sawdust & 0.95 & 430 & 22.0 & 19.5 \\
\hline Average & & & 1.39 & 395 & 25.1 & 16.2 \\
\hline \multicolumn{7}{|c|}{ Fermented livestock dropping (FLD) } \\
\hline $\mathrm{J}$ & Swine dropping & - & 0.24 & 364 & 50.8 & 7.2 \\
\hline $\mathrm{K}$ & Swine dropping & - & 5.23 & 323 & 44.7 & 7.2 \\
\hline $\mathrm{L}$ & Poultry dropping & - & 1.00 & 305 & 48.5 & 6.3 \\
\hline M & Poultry dropping & - & 1.40 & 299 & 41.7 & 7.2 \\
\hline $\mathrm{N}$ & Poultry dropping & - & 1.04 & 267 & 52.5 & 5.1 \\
\hline $\mathrm{O}$ & Poultry dropping & - & 1.02 & 280 & 41.7 & 6.7 \\
\hline Average & & & 1.65 & 306 & 46.7 & 6.6 \\
\hline
\end{tabular}

As, pseudo-total arsenic determined by digestion with aqua regia and perchloric acid; $\mathrm{C}$ and $\mathrm{N}$, total carbon and nitrogen, respectively, determined by a dry combustion method; $\mathrm{C} / \mathrm{N}$, the ratio of total carbon to nitrogen
The concentration of As and Fe in diluted soil solution was determined with inductively coupled plasma mass spectrometry (ICP-MS: Elan DRCe; PerkinElmer, Waltham, MA, USA) and inductively coupled plasma optical emission spectrometry (ICP-OES: Agilent 700 Series; Agilent Technologies, Santa Clara, CA, USA), respectively. A high-performance liquid chromatography/ICPMS (column: Discovery HS F5, $25 \mathrm{~cm} \times 4.6 \mathrm{~mm}, 5-\mu \mathrm{m}$ particles, Sigma-Aldrich, St. Louis, MO, USA; eluent composition [isocratic elution]: $1 \mathrm{~g} \mathrm{~kg}^{-1}$ formic acid, $30 \mathrm{~g} \mathrm{~kg}^{-1}$ methanol; flow rate: $1 \mathrm{~mL} \mathrm{~min}^{-1}$; spectrometer: Elan DRCe, PerkinElmer) was used for As speciation. The speciation was analyzed within $48 \mathrm{~h}$ after solution sampling to avoid As(III) oxidation during storage.

To measure the DOC in selected soil samples, the soil solution was collected using a syringe needle with a $1-\mu \mathrm{m}$ glass filter (Advanced Microdevices Pvt., Ltd, Ambala Cantt, India) before the sampling for dissolved As and $\mathrm{Fe}$ analysis. The filtrate was immediately acidified to about $\mathrm{pH}$ 2 to avoid Fe hydroxide precipitation. Then, the mixture was purged with $\mathrm{N}_{2}$ gas to remove inorganic carbon and stored at $4{ }^{\circ} \mathrm{C}$ until analysis. The DOC in the solution was determined using a total organic carbon analyzer (TOC5000; Shimadzu, Kyoto, Japan) within 5 days after solution sampling.

\section{Extraction and measurement of ferrous iron in incubated soils}

The Fe(II) produced in selected soils was extracted with sodium acetate according to Kumada and Asami (1957), with some modification. Two hundred and twenty milliliters of sodium acetate solution $\left(3 \mathrm{~mol} \mathrm{~L}^{-1}, \mathrm{pH} 2.5\right)$ and incubated soil (with soil solution) in vial were mixed in a 250-mL polyethylene bottle. The mixture was mechanically shaken for $2 \mathrm{~h}$ at room temperature. Aliquots of the mixture was collected in $50-\mathrm{mL}$ polyethylene centrifuge tubes and then centrifuged for $5 \mathrm{~min}$ at $3500 \mathrm{r} / \mathrm{min}$ $(1700 \mathrm{~g})$. The obtained supernatant was passed through a $0.2-\mu \mathrm{m}$ mesh membrane filter, and the filtrate was then diluted with ultra-pure water. Because almost all of the extracted Fe was Fe(II) (Kumada and Asami 1957), the total extracted Fe measured by ICP-OES (Agilent 700 Series; Agilent Technologies) was used as Fe(II).

\section{Data analysis}

The data obtained were statistically analyzed using $R$ software (version 3.2.2) including EZR (version 1.31) on $R$ commander (version 2.2-3). Correlation analyses among dissolved As and $\mathrm{Fe}$, soil $\mathrm{Eh}$, and amendment $\mathrm{C} / \mathrm{N}$ were 
carried out by Spearman's rank correlation test because of their potential nonlinear relationships.

\section{Results and discussion}

\section{Soils without organic amendments}

The $\mathrm{pH}$ of unamended soil rapidly increased to approximately 6.7, while soil Eh rapidly decreased to $-20 \mathrm{mV}$ with time and become stable (Fig. 1). The amounts of dissolved $\mathrm{As}, \mathrm{Fe}$, and $\mathrm{Fe}$ (II) in the flooded soils increased with time and reached a plateau of approximately $1.6 \mathrm{mg} \mathrm{kg}^{-1}, 0.8 \mathrm{~g} \mathrm{~kg}^{-1}$, and $16 \mathrm{~g} \mathrm{~kg}^{-1}$, respectively (Fig. 2a, b). The calculated amounts of remaining Fe oxides in the soil decreased from 34.1 to $18.2 \mathrm{gFe} \mathrm{kg}^{-1}$, corresponding to the increase in Fe(II) (Fig. 2b).

It is well known that low soil redox potential (low Eh) promotes As solubilization from soils (Marin et al. 1993; Hindersmann and Mansfeldt 2014). Because Fe oxides bind most of the As in soils (Hall et al. 1996; Cancès et al. 2008), the reductive dissolution of these oxides potentially solubilizes substantial amounts of As. Easily reducible Fe oxides are expected to retain As more than hardly reducible $\mathrm{Fe}$ oxides do, because of their potentially greater specific surface area. Therefore, the ratio of dissolved As to produced $\mathrm{Fe}(\mathrm{II})(\mathrm{As} / \mathrm{Fe}(\mathrm{II}))$ was expected to decrease with time; however, As/Fe(II) conversely increased with time (Fig. 3).

Islam et al. (2004) demonstrated that microbial Fe(III) reduction takes place prior to $\mathrm{As}(\mathrm{V})$ reduction in sediment, rather than simultaneously. Arsenic(III), the product resulting from $\mathrm{As}(\mathrm{V})$ reduction, has a smaller sorption distribution coefficient between solid to solution than $\mathrm{As}(\mathrm{V})$ in soils (Takahashi et al. 2003). On the basis of these facts and the suggestion by Burnol et al. (2007), who examined mechanisms for decoupling of As and Fe release from As-doped ferrihydrite by Fe-reducing bacteria, the

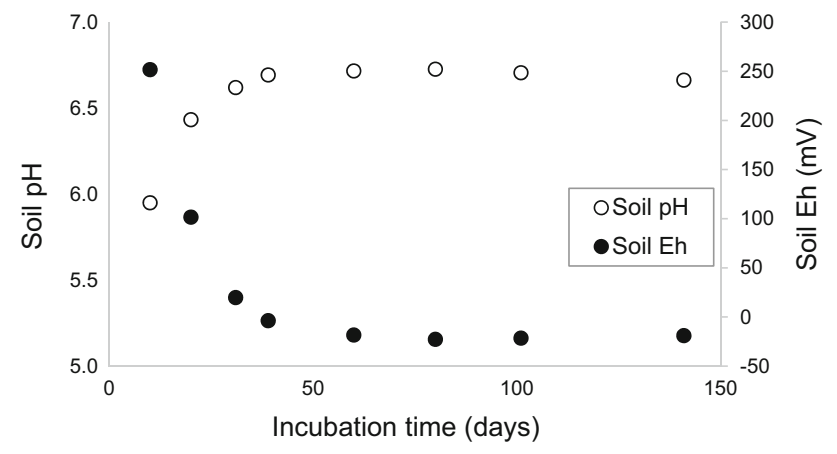

Fig. 1 Time course changes in soil $\mathrm{pH}$ and Eh during flooded incubation without organic amendment. Error bars indicate mean \pm standard deviation $(n=3)$
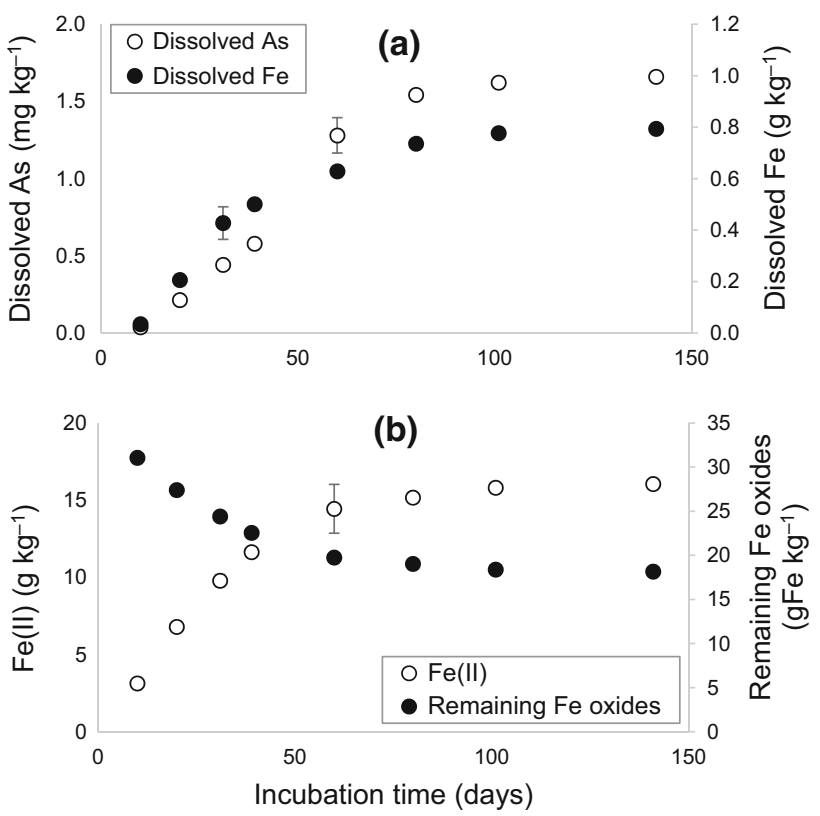

Fig. 2 Time course changes during incubation of flooded soil a of dissolved arsenic (As) and iron ( $\mathrm{Fe}$ ) and $\mathbf{b} \mathrm{Fe}(\mathrm{II})$ and remaining $\mathrm{Fe}$ oxides, without organic amendments. Error bars indicate mean $\pm \mathrm{s}$ tandard deviation $(n=3)$

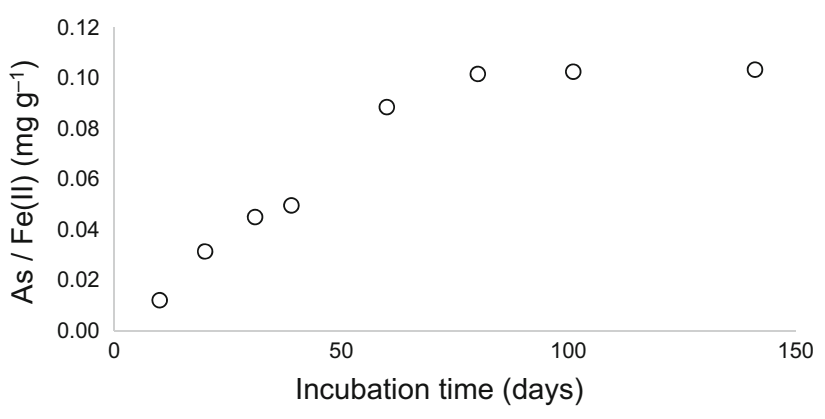

Fig. 3 Time course changes during incubation of flood soil of the ratio of dissolved arsenic to $\operatorname{iron}(\mathrm{II})(\mathrm{As} / \mathrm{Fe}(\mathrm{II})$ ) without organic amendments

increase in $\mathrm{As} / \mathrm{Fe}$ (II) indicates the presence of the following As solubilizing mechanisms. Early on, released As $(\mathrm{V})$ from reductively dissolved $\mathrm{Fe}$ oxides was not reduced but resorbed onto the remaining solid phase, resulting in the limited increase in dissolved As. When Eh decreased enough to favor reduced $\mathrm{As}(\mathrm{V})$, As would be released from dissolving $\mathrm{Fe}$ oxides with less resorption, and the reduction in the originally sorbed and resorbed $\mathrm{As}(\mathrm{V})$ on solid phase would accelerate As solubilization as As(III). Furthermore, the decrease in free Fe oxides that are the dominant As sorbent even under reducing conditions (Mitsunobu et al. 2006) (Fig. 2b) would result in increasing As distribution ratio to solution phase. Therefore, it would appear that the release of As from reductively dissolved $\mathrm{Fe}$ 
oxides was just one of the As solubilizing processes. Probably, the change in the As distribution ratio between solution and solid phase, which was affected by factors like As speciation, was the critical determinant for As solubility in the flooded soil.

\section{Soils with organic amendments}

The amounts of dissolved As in soils with OAs and control soils at 10,39, and 80 days of incubation are listed in Table 2. The dissolved As increased up to day 80 and reached from 1.5 to $1.6 \mathrm{mg} \mathrm{kg}^{-1}$ in all soils. The addition of all FLDs and two CMs significantly increased dissolved As, although the effect disappeared before day 80 . The average ratio of dissolved As in soils with OAs to control soils increased in the order: PCBs $<$ CMs $\ll$ FLDs in the case of days 10 and 39. The value for FLDs was significantly higher than for the others (Tukey's test, $P<0.05$ ) (Fig. 4). These facts strongly indicate that FLDs potentially pose a greater potential risk of As solubilization in flooded soils than PBCs and CMs.

Table 2 Amounts of dissolved arsenic (As) in soils with or without organic amendments

\begin{tabular}{|c|c|c|c|}
\hline \multirow[t]{2}{*}{ Amendment } & \multicolumn{3}{|c|}{ Dissolved As $\left(\mathrm{mg} \mathrm{kg}^{-1}\right)^{\mathrm{a}}$} \\
\hline & Day 10 & Day 39 & Day 80 \\
\hline Control & $0.037 \pm 0.006$ & $0.45 \pm 0.03$ & $1.57 \pm 0.01$ \\
\hline \multicolumn{4}{|c|}{ Plant-based compost (PBC) } \\
\hline A & $0.039 \pm 0.017$ & $0.48 \pm 0.11$ & $1.57 \pm 0.02$ \\
\hline B & $0.039 \pm 0.013$ & $0.42 \pm 0.01$ & $1.56 \pm 0.02$ \\
\hline $\mathrm{C}$ & $0.053 \pm 0.018$ & $0.39 \pm 0.01$ & $1.54 \pm 0.04$ \\
\hline $\mathrm{D}$ & $0.027 \pm 0.004$ & $0.39 \pm 0.04$ & $1.53 \pm 0.04$ \\
\hline $\mathrm{E}$ & $0.030 \pm 0.006$ & $0.40 \pm 0.03$ & $1.54 \pm 0.00$ \\
\hline Average & $0.038 \pm 0.010$ & $0.42 \pm 0.04$ & $1.55 \pm 0.01$ \\
\hline \multicolumn{4}{|c|}{ Cattle manure $(\mathrm{CM})$} \\
\hline $\mathrm{F}$ & $0.055 \pm 0.016$ & $0.58 \pm 0.07 *$ & $1.58 \pm 0.02$ \\
\hline G & $0.059 \pm 0.006$ & $0.73 \pm 0.02 * * *$ & $1.55 \pm 0.02$ \\
\hline $\mathrm{H}$ & $0.038 \pm 0.015$ & $0.44 \pm 0.09$ & $1.56 \pm 0.02$ \\
\hline I & $0.059 \pm 0.034$ & $0.43 \pm 0.10$ & $1.55 \pm 0.04$ \\
\hline Average & $0.053 \pm 0.010$ & $0.55 \pm 0.14$ & $1.56 \pm 0.02$ \\
\hline \multicolumn{4}{|c|}{ Fermented livestock dropping (FLD) } \\
\hline $\mathrm{J}$ & $0.146 \pm 0.023 * * *$ & $1.09 \pm 0.00^{* * *}$ & $1.60 \pm 0.01$ \\
\hline $\mathrm{K}$ & $0.096 \pm 0.002 * *$ & $0.90 \pm 0.04 * * *$ & $1.48 \pm 0.02$ \\
\hline $\mathrm{L}$ & $0.295 \pm 0.026 * * *$ & $1.32 \pm 0.01 * * *$ & $1.48 \pm 0.02 * * *$ \\
\hline M & $0.265 \pm 0.040^{* * *}$ & $1.29 \pm 0.02 * * *$ & $1.49 \pm 0.01 * *$ \\
\hline $\mathrm{N}$ & $0.267 \pm 0.023 * * *$ & $1.27 \pm 0.02 * * *$ & $1.49 \pm 0.00 * *$ \\
\hline $\mathrm{O}$ & $0.258 \pm 0.023 * * *$ & $1.27 \pm 0.01 * * *$ & $1.49 \pm 0.03 * *$ \\
\hline Average & $0.221 \pm 0.080$ & $1.19 \pm 0.16^{* * *}$ & $1.51 \pm 0.04$ \\
\hline
\end{tabular}

${ }^{a}$ Asterisks denote a significant difference between the control soil and soil with organic amendment; significance levels are $5 \%(*), 1 \%$ $(* *)$, and $0.1 \%(* * *)$

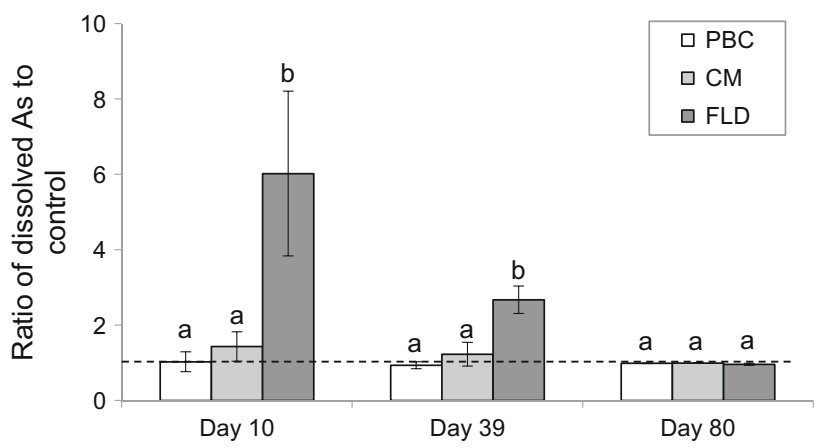

Fig. 4 Average relative ratios of dissolved arsenic (As) in soils with each type of organic amendments and in control soils. The broken line indicates the ratio $=1$. PBC, CM, and FLD indicate plant-based compost, cattle manure, and fermented livestock dropping, respectively. Error bars indicate mean \pm standard deviation. Different letters on the same day denote significant difference at $P=0.05$ (Tukey's test)

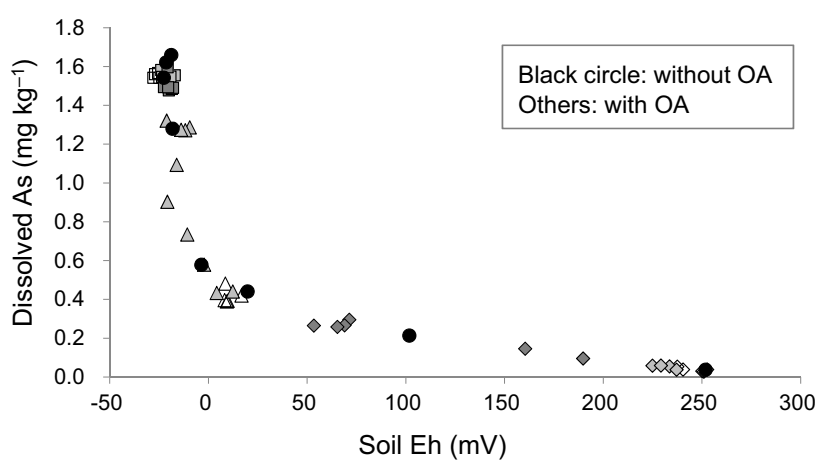

Fig. 5 Relationship between dissolved arsenic (As) and soil Eh with or without organic amendments (OAs) $(n=3)$ : Black circular spots denote control soils on days 10, 20,31,39, 60, 80, 100, and 141 from right to left. White, light gray, and dark gray symbols indicate soils with plant-based composts, cattle manures, and fermented livestock droppings, respectively. Rhomboid, triangular, and square symbols denote soils with OAs at days 10,39 , and 80

Figure 5 shows the relationship between dissolved As and soil Eh with/without OAs. As expected, the dissolved arsenic increased with decreasing soil Eh regardless of the addition of OAs. Noteworthy is that the addition of OAs did not substantially change the relationship between dissolved As and soil Eh. This means that the increase in dissolved As by the addition of OAs could be mostly explained by the acceleration of soil reduction. Thus, reactions irrelevant to redox reaction in soils, such as increase in DOC, could not be a major cause for the As solubilization associated with the addition of OAs. Other data also support this consideration. The soils with amendments J (FLD) and L (FLD) contained significantly greater amounts of DOC (24 and $29 \%$, respectively) than the control soils did, even at day 80 (Table 3), while no increase in dissolved As at day 80 was observed (Table 2). 
Table 3 Amounts of dissolved organic carbon (DOC) in soils with or without organic amendments

\begin{tabular}{lcll}
\hline Amendment $^{\mathrm{a}}$ & Day 11 & Day 39 & Day 80 \\
\hline DOC $\left(\mathrm{mg} \mathrm{kg}^{-1}\right)$ & & & \\
Control & $84 \pm 1 \mathrm{a}$ & $163 \pm 9 \mathrm{a}$ & $170 \pm 9 \mathrm{a}$ \\
A (PBC) & $93 \pm 3 \mathrm{a}$ & $174 \pm 3 \mathrm{a}$ & $196 \pm 14 \mathrm{ab}$ \\
F (CM) & $113 \pm 10 \mathrm{~b}$ & $191 \pm 5 \mathrm{ab}$ & $203 \pm 10 \mathrm{~b}$ \\
J (FLD) & $214 \pm 7 \mathrm{c}$ & $229 \pm 20 \mathrm{bc}$ & $211 \pm 4 \mathrm{~b}$ \\
L (FLD) & $248 \pm 11 \mathrm{~d}$ & $224 \pm 16 \mathrm{c}$ & $220 \pm 13 \mathrm{~b}$ \\
\hline
\end{tabular}

Different letters in the same column denote significant difference at $P=0.05$ (Tukey's test)

a $P B C$ plant-based compost, $C M$ cattle manure, $F L D$ fermented livestock dropping

The As solubilizing effect of DOC (Grafe et al. 2001; Bauer and Blodau 2006) and other potential competing ions such as carbonate species (Brechbühl et al. 2012; Violante and Pigna; 2002; Waltham and Eick 2002) were probably masked by the greater contribution of the decrease in soil Eh. Therefore, the decrease in soil Eh was mainly responsible for the increase in dissolved As with the application of FLDs and two CMs.

Because microbial activities promote soil reduction, the bio-decomposability of the added OAs would control soil Eh. Soil Eh controlled As solubility in soils, as mentioned above; therefore, bio-decomposability of the OAs should be the most important consideration for As risk management associated with OAs applications. The carbon/nitrogen ratio of organic matter generally relates to their biodecomposability; organic matter with lower $\mathrm{C} / \mathrm{N}$ is decomposed easier than that with higher $\mathrm{C} / \mathrm{N}$ (Huang et al. 2004). As expected, amendment $\mathrm{C} / \mathrm{N}$ and soil Eh were significantly and positively correlated at days 10 and 39 (Spearman's rank test, Table 4). Conversely, the dissolved As was negatively correlated with amendment $\mathrm{C} / \mathrm{N}$, reflecting a negative relationship between dissolved As and soil Eh (Table 4). This fact is consistent with a model study by Solaiman et al. (2009), who demonstrated that As solubilization from As-doped $\mathrm{Fe}$ oxyhydroxide-coated sand was tightly regulated by $\mathrm{C} / \mathrm{N}$ of added $\mathrm{OA}$. Thus, amendment $\mathrm{C} / \mathrm{N}$ is potentially useful for comparing relative risk of OAs for accelerating As solubilization in flooded soils.

The relationships among dissolved $\mathrm{Fe}$, soil $\mathrm{Eh}$, and amendment $\mathrm{C} / \mathrm{N}$ showed similar trends (Table 4). The addition of $\mathrm{OAs}$ with low $\mathrm{C} / \mathrm{N}$ decreased soil Eh and consequently promoted the reductive dissolution of $\mathrm{Fe}$ oxides. The rank correlation coefficients between dissolved As and Fe were remarkably high $\left(r_{\mathrm{s}}=0.989, P<0.001\right.$ for Day 10 and $r_{\mathrm{s}}=0.993, P<0.001$ for Day 39). However, considering the discussion in "Soils without organic amendments" section, As released from reductively dissolved Fe oxides should not directly and dominantly contribute to the increase in dissolved As without $\mathrm{As}(\mathrm{V})$ reduction. The strong rank correlation should only be interpreted to mean that the soil conditions favorable for $\mathrm{Fe}$ (III) reduction were also favorable for As solubilization.

Arsenic speciation in the soil solution is shown in Table 5. The percentage of $\mathrm{As}(\mathrm{V})$ to total As was decreased in the order: control $=\mathrm{A}(\mathrm{PBC})>\mathrm{F}(\mathrm{CM}) \gg \mathrm{J}$ and $\mathrm{L}$ (FLD) $(<2 \%$ of total As) at Day 10 (Table 5). This order was similar to that for soil Eh: $\operatorname{control}=\mathrm{A}$ $(\mathrm{PBC})>\mathrm{F}(\mathrm{CM}) \gg \mathrm{J}(\mathrm{FLD})>\mathrm{L}$ (FLD). Thus, the addition of some OAs evidently accelerated $\mathrm{As}(\mathrm{V})$ reduction in soil solution by inducing chemical reduction in the soil. Although $\mathrm{As}(\mathrm{V})$ in all measured soil solutions was marginally diminished $(<2 \%)$, even at day 39 , a substantial amount of $\mathrm{As}(\mathrm{V})$ likely remained in solid phase judging from previous studies (Weber et al. 2010; Yamaguchi et al. 2011). This is because the microbial reduction in $\mathrm{As}(\mathrm{V})$ in solution phase is much faster than that in solid phase (Jones et al. 2000). Therefore, the acceleration of As solubilization through $\mathrm{As}(\mathrm{V})$ reduction associated with the addition of OAs probably continued even after day 39.
Table 4 Spearman's rank correlation coefficients between several parameters at days 10 (above the line) and 39 (below the line)

\begin{tabular}{lllll}
\hline Parameter & Dissolved As & Dissolved Fe & Soil Eh & Amendment C/N \\
\hline \hline Dissolved As & & $0.989^{* * *}$ & $-0.925^{* * *}$ & $-0.821^{* * *}$ \\
Dissolved Fe & $0.993^{* * *}$ & & $-0.932^{* * *}$ & $-0.800^{* * *}$ \\
Soil Eh & $-0.821^{* * *}$ & $-0.807^{* * *}$ & & $0.854^{* * *}$ \\
Amendment C/N & $-0.818^{* * *}$ & $-0.800^{* * *}$ & $0.821^{* * *}$ & \\
\hline
\end{tabular}

As, arsenic; $\mathrm{Fe}$, iron; $\mathrm{C} / \mathrm{N}$, the ratio of carbon to nitrogen

a Asterisks denote a significant difference between the control soil and soil with organic amendment; the significance levels are $5 \%(*), 1 \%(* *)$, and $0.1 \%(* * *)$ 
Table 5 Percentage of pentavalent arsenic $(\mathrm{As}(\mathrm{V}))$ and soil Eh with or without organic amendments

\begin{tabular}{llll}
\hline Amendment $^{\mathrm{a}}$ & Day 11 & Day 39 & Day 80 \\
\hline As(V) $\%^{\mathrm{b}}$ & & & \\
Control & $9.09 \pm 1.77 \mathrm{a}$ & $<2$ & n.a. \\
A (PBC) & $8.50 \pm 3.95 \mathrm{a}$ & $<2$ & n.a. \\
F (CM) & $2.46 \pm 1.95 \mathrm{~b}$ & $<2$ & n.a. \\
J (FLD) & $<2$ & $<2$ & n.a. \\
L (FLD) & $<2$ & $<2$ & n.a. \\
Soil Eh (mV) & & & \\
Control & $249 \pm 4 \mathrm{a}$ & $13 \pm 4 \mathrm{a}$ & $-23 \pm 2 \mathrm{a}$ \\
A (PBC) & $245 \pm 3 \mathrm{a}$ & $9 \pm 3 \mathrm{ab}$ & $-26 \pm 5 \mathrm{a}$ \\
F (CM) & $220 \pm 6 \mathrm{~b}$ & $-2 \pm 5 \mathrm{~b}$ & $-24 \pm 4 \mathrm{a}$ \\
J (FLD) & $127 \pm 2 \mathrm{c}$ & $-16 \pm 8 \mathrm{c}$ & $-21 \pm 6 \mathrm{a}$ \\
L (FLD) & $50 \pm 4 \mathrm{~d}$ & $-21 \pm 4 \mathrm{c}$ & $-19 \pm 3 \mathrm{a}$ \\
\hline
\end{tabular}

Different letters in the same column denote significant difference at $P=0.05$ (Tukey's test)

a $P B C$ plant-based compost, $C M$ cattle manure, $F L D$ fermented livestock dropping

${ }^{b}$ Percentage of $\mathrm{As}(\mathrm{V})$ to total As in soil solution

\section{Implication and further studies}

Dissolved As generally has been considered an indicator for As availability, although some researchers pointed out that it is not a good predictor for As uptake by rice (Williams et al. 2011; Norton et al. 2013). The addition of OAs potentially increases (Xie and Huang 1998; Suda et al. 2015) and decreases (Das et al. 2005) dissolved As through a variety of mechanisms (see "Introduction" section). The present study showed different effects of three types of OAs on As solubility. Fermented livestock (swine and poultry) droppings posed a significantly higher risk of As solubilization, while PBC and most CMs did not.

The OAs used here are well-decomposed or well-fermented amendments. Therefore, a significant strong negative rank correlation between amendment $\mathrm{C} / \mathrm{N}$ and soil $\mathrm{Eh}$ was observed, indicating that $\mathrm{C} / \mathrm{N}$ worked well as an indicator for bio-decomposability of amendments. However, amendment $\mathrm{C} / \mathrm{N}$ would not imply the decomposability of immature OAs, which have very high $\mathrm{C} / \mathrm{N}$ but contain a great amount of easily decomposable organic matter. For example, Ma et al. (2014) showed that straw incorporation significantly increased As in rice grains grown on continuously flooded soils. Although they did not show the straw $\mathrm{C} / \mathrm{N}$ and dissolved As, amendment $\mathrm{C} / \mathrm{N}$ obviously cannot predict the increase in As risk of rice when immature amendments are used. Therefore, better indicators that could be applied to various types of OAs should be established in further studies.

Because As solubilization with OAs could mostly be explained by the decrease in soil Eh, probably increasing
As risk of rice could be prevented by application with the proper timing. In the present study, the averaged relative ratio of dissolved As in soils with FLDs decreased with time, indicating that the As risk of FLDs decreased with time. Generally, waiting a long time from the application of OAs to waterlogging would be useful for decreasing decomposable organic matter. This would alleviate a decrease in soil Eh and subsequent increase in As solubilization. Honma et al. (2012) demonstrated that As in the rice grains increased with application of molasses at heading or one week after heading, while it did not change after early application (one week before heading). Water management might be also important to attenuate As risk associated with application of OAs. Ma et al. (2014) showed that an increase in grain As with straw incorporation combined with intermittent flooding was much less than those with continuous flooding. Thus, although the application of some OAs, especially FLDs, poses a higher risk of As solubilization, probably overall risk of As accumulation could be prevented by proper agricultural management.

\section{Conclusion}

Dissolved arsenic and produced iron(II) in unamended soils increased with incubation time through the reduction in $\operatorname{arsenic}(\mathrm{V})$ and arsenic-bearing iron oxides, but they were not coupled. The addition of fermented livestock droppings has much greater potential to increase the risk of arsenic solubilization than plant-based composts and cattle manures. The solubilization of arsenic with the application of organic amendments could mostly be explained by their effect in promoting chemical reduction in the soil. This fact indicates that arsenic solubilization is favored when fermented livestock droppings are used, due to their high biodecomposability.

Acknowledgments We acknowledge Dr. Tomohito Arao, Dr. Akira Kawasaki, Dr. Noriko Yamaguchi, Dr. Yuji Maejima, Dr. Ken Nakamura, Dr. Kazunori Minamikawa, and Dr. Ikuko Akahane for their useful suggestions. This work was supported by a Grant-in-Aid from the Ministry of Agriculture, Forestry and Fisheries in Japan (Research Project for Improving Food Safety and Animal Health, As210).

\section{References}

Bauer M, Blodau C (2006) Mobilization of arsenic by dissolved organic matter from iron oxides, soils and sediments. Sci Total Environ 354:179-190. doi:10.1016/j.scitotenv.2005.01.027

Bissen M, Frimmel FH (2000) Speciation of As(III), As(V), MMA and DMA in contaminated soil extracts by HPLC-ICP/MS. Fresenius J Anal Chem 367:51-55. doi:10.1007/s002160051597 
Brechbühl Y, Christl I, Elzinga EJ, Kretzschmar R (2012) Competitive sorption of carbonate and arsenic to hematite: combined ATR-FTIR and batch experiments. J Colloid Interface Sci 377:313-321. doi:10.1016/j.jcis.2012.03.025

Burnol A, Garrido F, Baranger P et al (2007) Decoupling of arsenic and iron release from ferrihydrite suspension under reducing conditions: a biogeochemical model. Geochem Trans 8:12. doi:10.1186/1467-4866-8-12

Buschmann J, Kappeler A, Lindauer U et al (2006) Arsenite and arsenate binding to dissolved humic acids: influence of $\mathrm{pH}$, type of humic acid, and aluminum. Environ Sci Technol 40:6015-6020. doi:10.1021/es061057+

Cancès B, Juillot F, Morin G et al (2008) Changes in arsenic speciation through a contaminated soil profile: a XAS based study. Sci Total Environ 397:178-189. doi:10.1016/j.scitotenv. 2008.02.023

Das DK, Garai TK, Sarkar S, Sur P (2005) Interaction of arsenic with zinc and organics in a rice (Oryza sativa L.) — cultivated field in India. Sci World J 5:646-651. doi:10.1100/tsw.2005.60

Grafe M, Eick MJ, Grossl PR (2001) Adsorption of arsenate (V) and arsenite (III) on goethite in the presence and absence of dissolved organic carbon. Soil Sci Soc Am J 65:1680-1687

Hall GEM, Gauthier G, Pelchat JC et al (1996) Application of a sequential extraction scheme to ten geological certified reference materials for the determination of 20 elements. J Anal At Spectrom 11:787-796. doi:10.1039/ja9961100787

Hindersmann I, Mansfeldt T (2014) Trace element solubility in a multimetal-contaminated soil as affected by redox conditions. Water Air Soil Pollut 225:2158. doi:10.1007/s11270-014-2158-8

Honma T, Kaneko A, Ohba H, Ohyama T (2012) Effect of application of molasses to paddy soil on the concentration of cadmium and arsenic in rice grain. Soil Sci Plant Nutr 58:255-260. doi:10. 1080/00380768.2012.670809

Huang Y, Zou J, Zheng X et al (2004) Nitrous oxide emissions as influenced by amendment of plant residues with different C:N ratios. Soil Biol Biochem 36:973-981. doi:10.1016/j.soilbio. 2004.02.009

Islam FS, Gault AG, Boothman C et al (2004) Role of metal-reducing bacteria in arsenic release from Bengal delta sediments. Nature 430:68-71. doi:10.1038/nature02638

Jain CK, Ali I (2000) Arsenic: occurrence, toxicity and speciation techniques. Water Res 34:4304-4312. doi:10.1016/S00431354(00)00182-2

Jiang W, Zhang S, Shan XQ et al (2005) Adsorption of arsenate on soils. Part 2: modeling the relationship between adsorption capacity and soil physiochemical properties using 16 Chinese soils. Environ Pollut 138:285-289. doi:10.1016/j.envpol.2005.03.008

Jones CA, Langner HW, Anderson K et al (2000) Rates of microbially mediated arsenate reduction and solubilization. Soil Sci Soc Am J 64:600-608. doi:10.2136/sssaj2000.642600x

Kumada K, Asami T (1957) A new method for determining ferrous iron in paddy soils. Soil Sci Plant Nutr 3:187-193. doi:10.1080/ 00380768.1957.10431920

Langner P, Mikutta C, Kretzschmar R (2011) Arsenic sequestration by organic sulphur in peat. Nat Geosci 5:66-73. doi:10.1038/ngeo1329

Livesey NT, Huang PM (1981) Adsorption of arsenate by soils and its relation to selected chemical properties and anions. Soil Sci 131:88-94

Ma R, Shen J, Wu J et al (2014) Impact of agronomic practices on arsenic accumulation and speciation in rice grain. Environ Pollut 194:217-223. doi:10.1016/j.envpol.2014.08.004

Manning BA, Goldberg S (1997) Arsenic(III) and arsenic(V) adsorption on three California soils. Soil Sci 62:886-895

Marin A, Masscheleyn P, Patrick WH Jr (1993) Soil redox-pH stability of arsenic species and its influence on arsenic uptake by rice. Plant Soil 152:245-253
Mitsunobu S, Harada T, Takahashi Y (2006) Comparison of antimony behavior with that of arsenic under various soil redox conditions. Environ Sci Technol 40:7270-7276. doi:10.1021/es060694x

Mondal D, Polya DA (2008) Rice is a major exposure route for arsenic in Chakdaha block, Nadia district, West Bengal, India: a probabilistic risk assessment. Appl Geochem 23:2987-2998. doi:10.1016/j.apgeochem.2008.06.025

Norton GJ, Adomako EE, Deacon CM et al (2013) Effect of organic matter amendment, arsenic amendment and water management regime on rice grain arsenic species. Environ Pollut 177:38-47. doi:10.1016/j.envpol.2013.01.049

Oguri T, Yoshinaga J, Tao H, Nakazato T (2014) Inorganic arsenic in the Japanese diet: daily intake and source. Arch Environ Contam Toxicol 66:100-112. doi:10.1007/s00244-013-9947-8

Pongratz R (1998) Arsenic speciation in environmental samples of contaminated soil. Sci Total Environ 224:133-141. doi:10.1016/ S0048-9697(98)00321-0

Rahaman S, Sinha A, Mukhopadhyay D (2011) Effect of water regimes and organic matters on transport of arsenic in summer rice (Oryza sativa L.). J Environ Sci 23:633-639

Solaiman ARM, Meharg AA, Gault AG, Charnock JM (2009) Arsenic mobilization from iron oxyhydroxides is regulated by organic matter carbon to nitrogen (C:N) ratio. Environ Int 35:480-484

Suda A, Baba K, Yamaguchi N et al (2015) The effects of soil amendments on arsenic concentrations in soil solutions after long-term flooded incubation. Soil Sci Plant Nutr 61:592-602. doi:10.1080/00380768.2015.1006119

Suda A, Baba K, Akahane I, Makino T (2016) Use of water-treatment residue containing polysilicate-iron to stabilize arsenic in flooded soils and attenuate arsenic uptake by rice plants. Soil Sci Plant Nutr 62:111-116. doi:10.1080/00380768.2015. 1137200

Takahashi Y, Ohtaku N, Mitsunobu S et al (2003) Determination of the $\mathrm{As}(\mathrm{III}) / \mathrm{As}(\mathrm{V})$ ratio in soil by $\mathrm{X}$-ray absorption near-edge structure (XANES) and its application to the arsenic distribution between soil and water. Anal Sci 19:891-896

Thanagalasingam P, Pickering WF (1986) Arsenic sorption by humic acids. Environ Pollut 12:233-246

Violante A, Pigna M (2002) Competitive sorption of arsenate and phosphate on different clay minerals and soils. Soil Sci Soc Am J 66:1788-1796

Waltham C, Eick M (2002) Kinetics of arsenic adsorption on goethite in the presence of sorbed silicic acid. Soil Sci Soc Am J 66:818-825

Wang S, Mulligan CN (2006) Effect of natural organic matter on arsenic release from soils and sediments into groundwater. Environ Geochem Health 28:197-214. doi:10.1007/s10653-005-9032-y

Weber F-A, Hofacker AF, Voegelin A, Kretzschmar R (2010) Temperature dependence and coupling of iron and arsenic reduction and release during flooding of a contaminated soil. Environ Sci Technol 44:116-122. doi:10.1021/es902100h

Williams PN, Villada A, Deacon C et al (2007) Greatly enhanced arsenic shoot assimilation in rice leads to elevated grain levels compared to wheat and barley. Environ Sci Technol 41:6854-6859. doi:10.1021/es070627i

Williams PN, Zhang H, Davison W et al (2011) Organic matter-solid phase interactions are critical for predicting arsenic release and plant uptake in Bangladesh paddy soils. Environ Sci Technol 45:6080-6087. doi:10.1021/es2003765

Xie ZM, Huang CY (1998) Control of arsenic toxicity in rice plants grown on an arsenic-polluted paddy soil. Commun Soil Sci Plant Anal 29:2471-2477. doi:10.1080/00103629809370125

Yamaguchi N, Nakamura T, Dong D et al (2011) Arsenic release from flooded paddy soils is influenced by speciation, $\mathrm{Eh}, \mathrm{pH}$, and iron dissolution. Chemosphere 83:925-932. doi:10.1016/j. chemosphere.2011.02.044 